\title{
Inventions Utilizing Satellite Navigation Systems in the Railway Industry - An Analysis of Patenting Activity
}

\author{
Pekka Salmi,' Marko Torkkeli ${ }^{2}$
}

\begin{abstract}
Applications based on the Global Navigation Satellite System (GNSS), in combination with different communication systems, have significantly helped to increase safety, efficiency and system capacity of operations in different modes of transportation. Here railway transport is no exception, although the number of applications based on GNSS has been considerably behind the number of those used in road transport. Since incorporating e.g. GPS receivers into modern signaling, train control and other railway systems has become usual, it is interesting to examine GNSS/GPS-based inventions and patenting trends more closely in this context. This paper analyses GNSS/GPS-related patents in the railway industry in order to shed light on the patenting activity in different countries/regions and to identify (and to a certain extent make a classification of) the main application areas for this technology.
\end{abstract}

Key words: Railways; transport; satellite navigation; GNSS; GPS; inventions; patents; signaling; train control.

\footnotetext{
' Department of Industrial Management, Lappeenranta University of Technology, Prikaatintie 9, FI-45I00 Kouvola, Finland. E-mail: pekka.salmi@lut.fi

${ }^{2}$ Department of Industrial Management, Lappeenranta University of Technology, Prikaatintie 9, FI-45I00 Kouvola, Finland. Phone +358 562 I I. E-mail: marko.torkkeli@lut.fi
} 


\section{Introduction}

Like in most other modes of transportation, high levels of safety, efficiency and system capacity of operations are among the key objectives of railway industry nowadays. Developing operations and services is important also because the industry has lost a significant share of transport volume in Europe during the last decades (especially in the area of freight transportation; see e.g. Hilmola, 2007). The increased competition with the other modes of transport, as well as between the different railway operators, means that the use of modern technologies and innovative solutions is crucial for the competitiveness of railway companies. An example of such technologies is the Global Positioning System (GPS) which, in combination with different communication systems, has significantly helped to reduce accidents and delays, and to improve capacity and cost effectiveness of transportation in general. Indeed, satellite navigation/positioning systems (the standard generic term is Global Navigation Satellite System, GNSS) and telecommunication systems have a lot of applications in the area of transportation today.

The rail system, however, differs from other modes of transportation in that there is less flexibility in managing the traffic. Moreover, regarding the use of GNSS, there is obviously no need for vehicle navigation systems as such. On the other hand, knowing the exact location of a train has many advantages, including more efficient traffic monitoring (which helps scheduling both in freight and passenger transportation and thus enhances connectivity with other modes of transportation) and logistic information management, enhanced train signaling (which improves safety, but also enables e.g. reduced distances between trains and therefore increased train frequencies), and the possibility to map the transport infrastructure. Thus, while the number of applications based on GNSS is considerably behind the number of those used in road transport, incorporating GPS receivers into modern signaling, train control and other railway systems has become usual. Furthermore, the utilization of GNSS in rail transportation has been recognized as an important research area at the European Union level. Projects such as GADEROS (Galileo Demonstrator for Railway Operation System), RUNE (Railway User Navigation Equipment), INTEGRAIL and most recently GRAIL (www.grail-project.com) were each aimed at supporting the introduction of GNSS in the railway sector (particularly in rail safety applications).

Since there has been a rapid growth in the number of patents related to GPS technology since the end of 1980s (see e.g. Yuan et al., 2007 for an analysis of the patent data from the United States Patent and Trademark Office), it is interesting to examine whether a similar trend can be seen also in the railway industry. In particular, while examining patenting activity and the number of patents issued each year does not accurately reflect the development of a technology, patent analysis is still useful e.g. in forecasting technology life cycles (Haupt et al., 2007). In this paper, we will therefore make an analysis of GNSS/GPS-related patents in the railway industry in order to shed light on the patenting activity in different countries/regions and to identify (and to a certain extent make a classification of) the main application areas for this technology. To this end, we will both examine the patent classification codes disclosed within the patents and make a content analysis of the patent descriptions.

The paper is organized as follows. In the next section we will briefly review GNSS/GPS technology and discuss a few of its applications in the land transportation systems. In particular, we will present some relevant examples of the utilization of GNSS in the railway sector. A patent analysis will be made in the third section, which describes the patent data and search process, as well as presents the main observed trends in patenting activity and the main application areas. The results and their practical implications will be discussed in the final section.

\section{GNSS/GPS technology and its applications in the land transportation systems}

GPS is currently the only fully functional satellite navigation system (e.g. the Russian GLONASS is still in development and the European Galileo is in the initial deployment phase, scheduled to be operational in 2013; http://en.wikipedia.org/wiki/GNSS). The system consists of a constellation of at least 24 (and up to 32) earth-orbiting satellites (there were $3 \mathrm{I}$ actively broadcasting satellites in December 2008) that transmit microwave signals, through which the system enables a GPS receiver to determine its location, speed, direction, and time. 
In the 1970s, GPS was originally intended for military purposes. However, in the 1980s, the US government made the system available for civilian use and it nowadays has a number of applications both for military and civilian users. In civilian use, the most often utilized benefit from GPS signals is the ability to determine the receiver's absolute location. Therefore GPS receivers are typically used as an aid to navigation or as surveying tools. On the other hand, many commercial applications combine GPS with communications and other technologies (see e.g. Pace et al., 1995, Ch. 4). In the following, we will focus on GPSbased applications in the field of land transportation, and especially in the railway traffic.

\section{Applications in the area of transportation}

In their overview of GPS applications in the area of transportation, Mintsis et al. (2004) identify vehicle fleet management and monitoring as one main category. This category refers primarily to automatic vehicle location (AVL) systems (e.g. Lobo, 1998), which enable monitoring and remote tracking of vehicles. AVL systems can be based on GPS/GIS (geographic information system) technologies as well as various communication technologies (such as GSM), so that the data obtained from GPS receivers can be transferred to an operating center. AVL systems are typically used to monitor public transport vehicles and e.g. Real-Time Passenger Information (RTPI) systems have become more commonplace in bus transport (on buses, at bus stops, as well as inside bus stations) in major European cities (Firmin, 2006). Further examples of AVL systems include ambulance management and emergency incident handling (Derekenaris et al., 200I), and dangerous goods transportation. Here GPS/GIS-based vehicle monitoring systems can provide route guidance and scheduling information for vehicles.

Moreover, GPS/GIS technologies can be integrated e.g. with engine management systems in order to collect onroad traffic data from a probe vehicle. This kind of system can provide data on GPS position, speed, distance traveled, engine performance, fuel consumption and so on for traffic congestion studies (Taylor et al., 2000). Another useful application of GPS technology in the area of transportation is mapping of transportation networks (roads and rail). High accuracy digital road maps are essential especially for the applications in Intelligent Transportation Systems (ITS), so there is a need to develop new approaches for utilizing GPS data in maps generation (Guo et al., 2007).

Of course, the above examples are only among the numerous successful land based transport systems currently utilizing satellite navigation technology. In recent years GNSS has also been used in such private and public road transport applications as: In-Vehicle Dynamic Route Guidance, Intelligent Speed Adaptation (for improved road safety), Road User Charging (to better manage congestion), and Traveler Information Systems (see e.g. Firmin, 2006).

\section{Applications in the railway sector}

One way to categorize different systems utilizing GNSS in the railway sector is to distinguish between safety-critical and non-safety-critical applications (cf. Marwedel \& Gebotys, 2004). Safety-critical applications include e.g. train control and signaling, which in Europe have been subjects to a standardization process in recent years (the main aim has been to improve interoperability). In particular, there is emerging a European standard for train control, signaling and traffic management called the European Rail Traffic Management System (ERTMS), which includes two layers that can rely on satellite navigation: the European Train Control System (ETCS) and the European Traffic Management Layer (ETML) [EC-DGTREN (2008)]. Of these, ETCS deals with control and signaling systems used e.g. in remote electronic braking, train diagnostics and train/wagon location monitoring, all of which are functions whose safety and accuracy could especially be improved through application of GNSS. For example, combining GNSS position data with traditional train sensor readings, such as odometry, can improve the ETCS location performance and therefore allow e.g. a safe discrimination between parallel tracks and track change at switches (this was one of the goals in the INTEGRAIL project; Bedrich and $\mathrm{Gu}, 2004)$. One has to note, however, that since the performance of GNSS positioning depends e.g. on the environmental conditions (multi-path and shadowing of signals; see e.g. Marais et al., 2004), it usually cannot be used as a sole means for determining location in a train control system. Yet, in places where there is no trackside equipment, GNSS positioning can contribute to high safety levels. Moreover, in cases where GNSS can replace trackside devices, it provides significant cost-benefits and enhanced interoperability (Gu, 2005). 
Another safety-critical area where accurate positioning data provided by GNSS can be used is rail track surveying. First, testing/inspection systems need to be synchronized with a positioning system, and here GNSS can provide more accurate data than traditional techniques, such as track circuits [EC-DGTREN (2008)]. Secondly, recent developments in remote monitoring system (which are typically based on a combination of GNSS/GIS technologies, wireless communications, signal processing and embedded computing) have become compact and relatively inexpensive, and can therefore be used on almost any rail vehicle (Nejikovsky and Keller, 2000). These kinds of solutions which enable real-time performance monitoring contribute significantly to safety since they allow quicker detection of defects than traditional methods which are based on separate periodical track inspections.

As a final example of safety-critical applications, one can mention the use of GNSS data in assisting carbody tilt control, which allows tilting trains to negotiate sharp curves at higher speed (thereby enabling shorter traveling times) and with less centrifugal force inside a car. Detecting the accurate running position is essential here and traditionally it has been calculated by monitoring the number of wheel revolutions and using the ground coils installed on the track as position reference points. However, GPS-based systems have been recently developed which allow a positioning accuracy equal to or higher than the conventional system (see e.g. Maki, 2005; one should note that in this case the running position was determined by a combination of GPS data, track curvature map and wheel rotating pulse count). Besides being a cheaper solution than ground-coil-based systems, another benefit of using GPS is that it allows the system to restore the location information in a second if the present location is lost due to wheels slip or some other reason (Sasaki, 2005).

Non-safety-critical applications, in turn, are mainly related to fleet management, goods tracking and other logistic information management. The ability to effectively track the location of goods and to estimate their delivery times is indeed as important in railway sector as in other modes of transportation. On the other hand, GNSS-based fleet management will also help to improve the performance of passenger transportation. Providing up-to-date information about the arrival and departure times of trains, especially when there are delays, is an essential part of good service
[EC-DGTREN (2008)]. Yet another non-safety-critical application, which was already mentioned in the previous section, is the use of GNSS positioning data in mapping of railroads (see e.g. Euler et al., 1996).

\section{An analysis of GNSS/GPS-related patents in the railway industry}

\section{Patent data and search process}

GNSS/GPS-related patents were searched from the Software for Intellectual Property (SIP, www.patentfamily.de) database. This database comprises presently more than 50 million documents from the following publicly available patent databases/offices: Inpadoc Database, US Patent and Trademark Office (USPTO), European Patent Office (DOCDB) and German Patent and Trademark Office.

More specifically, the database includes the following patent data:

- title, abstract, claims, description and Inpadoc legal status of a patent

- publication and filing number/date

- country code of the filing country

- applicant and inventor

- International Patent Classification (IPC)

The database enables one to search for patents according to their IPC classes, application/publication dates, filing country codes and inventor/applicant. Also full-text searches of patent abstracts, claims and descriptions are possible. In order to find relevant patents for the current analysis, we made a full-text search of titles and abstracts of patent applications (using Boolean OR-operation) with the keywords GPS, GNSS, Galileo, EGNOS, GLONASS, "navigation satellite" and "satellite navigation" (the last two search terms were added since most patent abstracts are in English). The search was restricted to IPC class B6I (Railways) and its subclasses. Date range for the query was not specified.

The patent search query from the SIP database initially produced 262 results. However, a significant fraction of these belong to a "patent family" (i.e., a collection of 
related patents published by different patent offices), which means that they have multiple patent numbers. The search results include a link to an Inpadoc patent family description, so we first went through the patent families for each of the patents (which had up to 35 members) and made a correspondence table of the patent identifiers. After comparing the patent numbers and in some cases also patent abstracts, 175 distinct inventions were identified (32 of these belong to a patent family including two or more patents). Furthermore, after making an initial content analysis of the patent abstracts and claims (see section 'A content analysis of the patents' for more details), it was found that two inventions actually did not include or utilize GNSS/GPS. Thus, the first screening phase yielded 173 patents that were applicable for the analysis.

\section{Observed trends in patenting}

Yearly development in patenting. When going through the patent families, the choice between duplicate patents was first made according to a filing date, i.e., the patent which had the earliest filing date was selected. If two or more patents from different databases had the same filing date, the patent number and country code was selected on the basis of the nationality of the inventor (or the company). The number of filed patent applications per year is shown in Figure I.

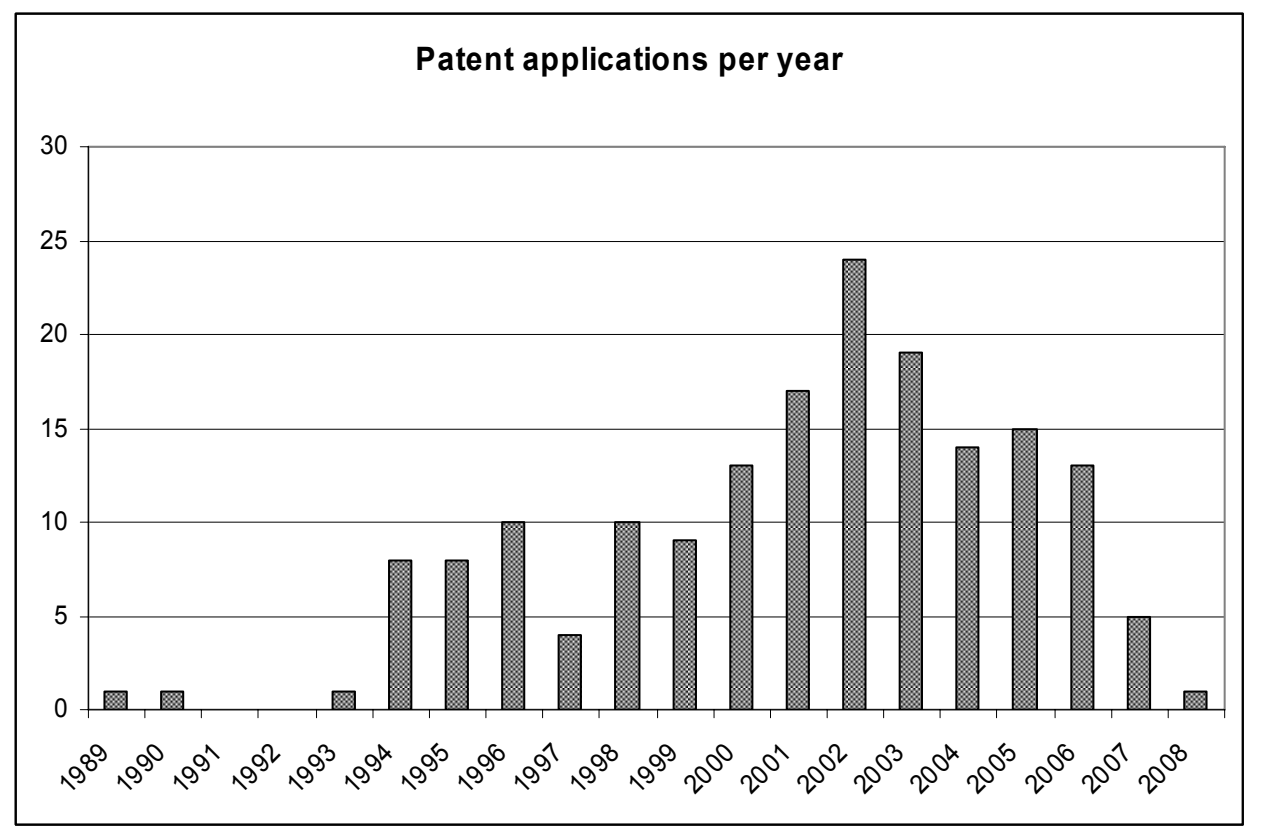

Figure I. GNSS/GPS-related patent applications in the railway industry per year.

As one can see, GNSS/GPS-related patent applications started to appear in increasing numbers from 1994 onwards. Before the year 2000, the number of applications per year was ten or less, but then increased sharply over the next three years (the number was 24 in 2002). However, after 2002 the number of patent applications started to decrease and was only five in 2007 (the number for 2008 does not cover the whole year). In order to see whether this kind of development is a characteristic of patenting in the railway industry or related to more general patenting trends, it is useful to compare the above numbers to the numbers of GNSS/GPS-related patent applications in general and also in other patent classes.
Since our data is comprised of only one patent family member for each of the invention, however, making comparisons to the numbers of patents searched from the SIP database without removing the duplicates would bias the results. To minimize this bias, we therefore applied the 'country' codes (i.e., patent database identifiers) WO (World Intellectual Property Organization) and US to the search and then retrieved the numbers of all GNSS/GPSrelated patents as well as the numbers of GNSS/GPSrelated patents belonging to an IPC class B60 (Vehicles in general) from the same period. The resulting numbers of patent applications are shown in Figure 2. 


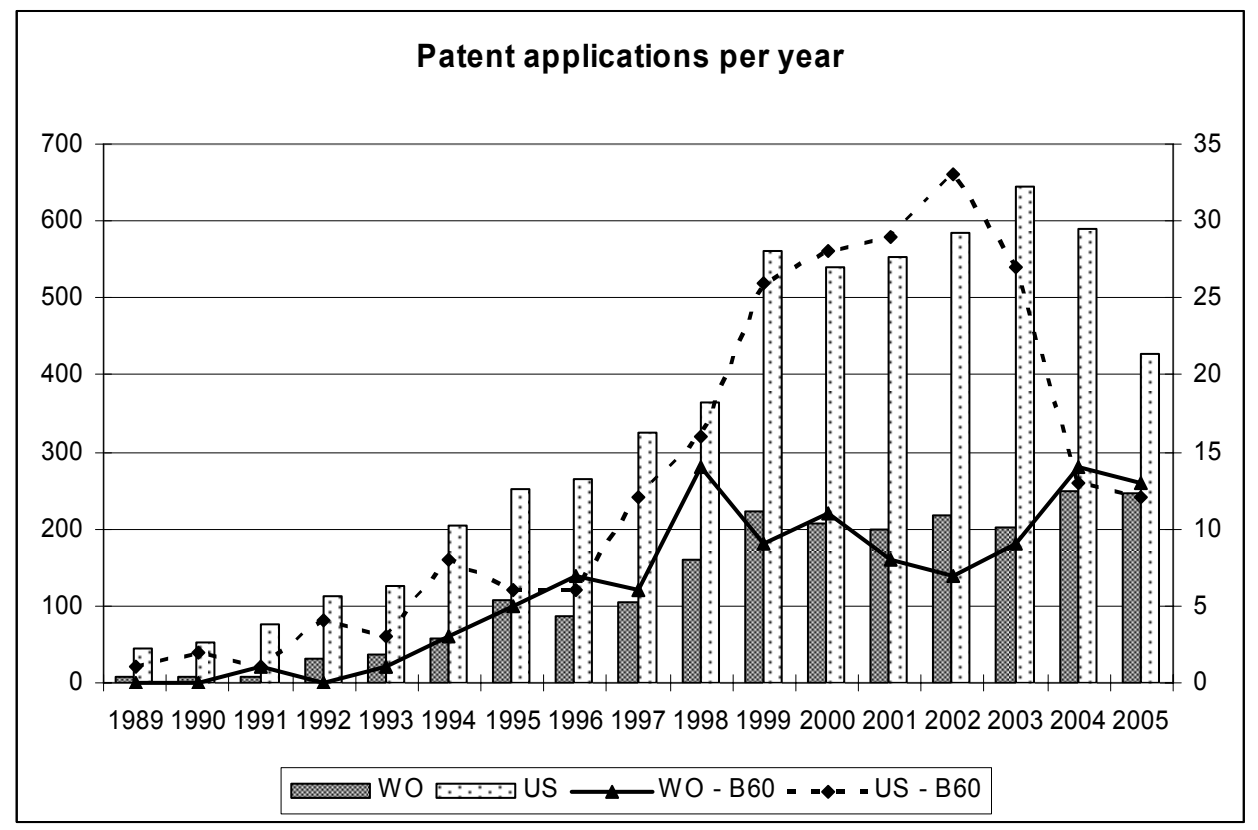

Figure 2. GNSS/GPS-related patent applications per year (under country codes WO and US).

A similar growth trend in patenting is evident in all four cases during the 1990s (especially during the latter half of the decade). It is therefore reasonable to assume that the increase in the number of patent applications at least partly reflects the fact that price and size/applicability of GPS equipment have been steadily declining since 1988 (Pace et al., 1995). There are significant differences between the two country codes in the number of patent applications after the year 2000, however. In particular, while the number of GNSS/GPS-related patent applications per year in the IPC class B60 more than doubles (from 16 to 33) between 2000 and 2004 for the US, for the WO it declines from 14 to 7 in the same period. On the other hand, the trends reverse for both country codes after 2004: especially, the number of applications for the US declines from 33 to 12. Of course, when the amount of patent applications per year is fairly small, one cannot make very strong conclusions about the development trends. Another interesting trend can be seen by comparing the numbers of all GNSS/GPS-related patent applications per year for the US and WO: the ratio of WO/US applications has been steadily increasing since the beginning of the 1990s (from 0.14 in 1990 to 0.57 in 2007).
Now, if the development of the number of GNSS/GPSrelated patent applications in the railway industry is compared to that in the class B60, one can see, for example by taking a yearly average for the US and WO (not shown), that the trend is fairly similar. In other words, the GNSS/GPS-related patenting trend in the railway industry is not atypical, but probably shows that after an initial surge of ideas the field of applications becomes saturated and the number of new ideas starts to slowly decline - especially since railway transport can be considered as a 'niche area' for GNSS/GPS-related inventions.

Patents' country of origin. The nationality of the inventor was in most cases reported in the applicant/inventor entry of the SIP database. However, in some cases the nationality was determined from the excluded member of the patent family and if there was no information about the inventor, the country of origin was determined by the patent's country code. The resulting distribution of patents according to their country of origin is shown in the following Table I. 


\begin{tabular}{|c|c|c|c|c|c|c|c|c|c|c|}
\hline $\begin{array}{l}\text { Country } \\
\text { code }\end{array}$ & $\mathbf{J P}$ & US & DE & CN & GB & RU & KR & ES & DK & Other \\
\hline $\begin{array}{l}\text { No. of } \\
\text { patents }\end{array}$ & 76 & 28 & 21 & 11 & 9 & 7 & 5 & 3 & 2 & 11 \\
\hline
\end{tabular}

Table I. Patent distribution according to the country of origin

While GNSS/GPS-related technical development and patenting activity in general have been strong in Japan, in the railway industry the country has a particularly significant lead with almost $44 \%$ share of patents included in the analysis. This is due to the fact that railway research in Japan has been very active both in the public sector (for example, Railway Technical Research Institute has five patent applications) as well as in the private sector. Indeed, several major Japanese corporations, such as Hitachi, Mitsubishi, Nippon Electric Co. and Matsushita have applied patents for GPS-related applications (the numbers of patent applications for these firms are 10, 9, 4 and 3, respectively).

The U.S. is in the second place in the number of patent applications largely because of General Electric which has been fairly active in patenting (with eight applications). After the U.S. come Germany, China and Great Britain, but in addition to Siemens from Germany (with three applications) other notable individual inventors/companies cannot be identified. The number of patent applications originating from rest of the countries is less than ten - in most cases only one.

\section{Application areas of patents}

Patent classifications. One way to explore various application areas of GNSS/GPS-related patents is to examine their IPC codes. Since B6I was used as a search limiter, all patents obviously include one or more classification codes for the subclasses of B6I (although in a few cases no classification codes were shown in the patent data). Also subclasses of GOI (Measuring) were included in most patents due to the fact that a satellite navigation system is utilized in the invention. However, several other main patent classes were referred to in the patent data as well. In total, the 173 patents included in the analysis disclosed 698 IPC codes and their distribution by the section and the first level number ("section symbol" and "class symbol") is shown in Table 2.

\begin{tabular}{|c|c|c|c|c|c|c|c|c|c|c|c|c|c|c|c|}
\hline \multirow{2}{*}{ IPC code } & B & & & & & E & $\mathbf{F}$ & G & & & & & & $\mathbf{H}$ & \\
\hline & 60 & 61 & 63 & 64 & 65 & 01 & 04 & 01 & 05 & 06 & 07 & 08 & 09 & 01 & 04 \\
\hline No. of codes & 26 & $\begin{array}{l}38 \\
7\end{array}$ & 1 & 1 & 4 & 10 & 1 & $\begin{array}{l}11 \\
8\end{array}$ & 8 & 33 & 4 & 56 & 6 & 4 & 39 \\
\hline
\end{tabular}

Table 2. The IPC section and class codes disclosed within the patents

First, one can note that there are 26 references to the class B60 (Vehicles in general) and 6 references to the classes B63, B64 and B65 of the section B (i.e.,
Transporting; the classes refer to 'ships', 'aircrafts' and 'conveying'), which shows that some of the inventions are not solely aimed at railway transport but can be applied to 
other forms of transport as well. Worth noticing is also that there are 10 references to the code EOI which refers to construction of railways. In this case, the invention (and positioning device) can be related e.g. to system which monitors the condition of a track or provides position information for track maintenance personnel. Regarding the section G, many patents disclose codes G06 and G08, which refer to computing and signaling, respectively. This may mean, for example, that in these inventions a positioning device is embedded in a larger operation control system. Finally, the code $\mathrm{H} 04$, which refers to 'Electronic communication technique', was included in the description of 39 patents related e.g. to various data transmission and train operation control systems.

If we examine the classification codes at the most detailed level (including also "subclass symbol", "group number" and "subgroup number"), the distribution of the most frequently used codes is as follows (Table 3):

\begin{tabular}{|c|c|c|c|c|c|c|c|c|c|c|}
\hline & & & & & & B6I & & B6I & & \\
\hline \multirow{3}{*}{$\begin{array}{l}\text { IPC } \\
\text { codes }\end{array}$} & B6I & B6I & B6I & G0I & B6I & L27/00; & B6I & K9/00; & B6I & H04 \\
\hline & $\mathrm{L} 25 / 00$ & $\mathrm{~L} 25 / 02$ & $\mathrm{~L} 23 / 00$ & $\mathrm{~S} 5 / 14$ & $\mathrm{~L} 3 / 00$ & GOI & L23/34 & B6I & L29/00 & $\mathrm{Q} 7 / 34$ \\
\hline & & & & & & $\mathrm{C} 21 / 00$ & & $\mathrm{~L} 3 / \mathrm{I} 2$ & & \\
\hline $\begin{array}{l}\text { No. of } \\
\text { codes }\end{array}$ & 79 & 75 & 43 & 33 & 25 & 23 & 13 & 12 & 11 & 10 \\
\hline
\end{tabular}

Table 3. The most frequently used IPC codes in the patents

As can be seen, 8 of the 12 most frequently used codes belong to the class B6I L: guiding railway traffic / ensuring the safety of railway traffic. First, inventions in the subclass L25 are related to "Recording or indicating positions or identities of vehicles or vehicle trains or setting of track apparatus", so it's unsurprising that so many patents include these codes. The descriptions of other disclosed $B 6 I L$ subclasses are the following:

- $\quad$ L3 - Devices along the route for controlling devices on the vehicle or vehicle train, e.g. to release brake, to operate a warning signal

- L23 - Control, warning or like safety means along the route or between vehicles or vehicle trains

- $\quad$ L27 - Central traffic control systems

- L29 - Safety means for rail/road crossing traffic

The frequency of these codes indicates that different safety and/or warning systems are the main application area of GNSS/GPS-related patents in the railway industry. That is, GNSS/GPS-based systems are typically used in measuring (safe) distances between trains, controlling their speed, indicating whether some vehicle approaches a safety critical area (e.g., a level crossing), and so on. Furthermore, the one remaining code under the class $\mathrm{B} 6 \mathrm{I}, \mathrm{K} 9 / 00$, refers to "Railway vehicle profile gauges; Detecting or indicating overheating of components; Apparatus on locomotives or cars to indicate bad track sections; General design of track recording vehicles" and is therefore also often disclosed in patents which aim at safety improvements.

Regarding the other classification codes, the subgroups under the class GOI (GOIS5/I4 and GOIC2I/00) refer to determining distances/positions and navigation. Finally, $\mathrm{H} 04 \mathrm{Q} 7 / 34$ refers to "Test or monitoring equipment" and is disclosed e.g. in patents which describe a system monitoring the relative distance between two vehicles and issuing a warning when the distance is inadequate.

A content analysis of the patents. Since the various codes and classes of IPC system examined above do not reflect very well different application areas of GNSS/GPSrelated inventions and the patent data in a few cases did not include a classification code, a content analysis of the patent abstracts and claims was made. The patent descriptions were read iteratively in order identify one or more key concepts for each invention. Eventually, after carefully reviewing the identified key concepts, seven main application areas were defined (see a summary in Table 4). At the outset one must note, however, that these classes are not intended to be mutually exclusive, but should rather capture the main feature and/or functionality of the 
invention. For example, while perhaps a majority of the patents could be seen to enhance safety in railway transport, only inventions which were aimed at avoiding accidents/collisions, included an automatic braking system, or otherwise were explicitly related to safety issues were classified under 'Safety systems'. Similarly, while almost all inventions included a GPS device for tracking a locomotive or specific wagons, patents were classified under 'Logistic management' only if their description mentioned a logistic operation. The brief descriptions of these areas are as follows:

I. Locomotive and railcar monitoring/tracking: Inventions is this class are mainly aimed at monitoring the position of a locomotive and/or railcars, so that one can automatically determine the length of a train, confirm its integrity, or otherwise ensure that the train has the right members (cars). One patent also describes a solution for detecting the track train is using (by monitoring locomotive turns) and is therefore included in this class.

2. Safety systems: This class includes various safety devices and systems for avoiding accidents and/or warning locomotive drivers (or other users) of hazards. These systems may, for example, control the speed of a train or apply brakes when necessary. One specific type of safety control is related to monitoring whether the train occupies a given track section or block.

3. Track monitoring: In this class, the patents describe systems which detect defects in the track, switches or rolling stock wheels, determine or record track condition (e.g. alignment), detect foreign objects, and so on.

4. Logistics management: Here positioning systems are typically used in locating/tracking e.g. containers on railcars. However, some of the inventions describe systems which aim at improving the performance of different logistic operations or making these operations automatic. They may, for example, support shunting operations, remote control of locomotives (in switching yards) or railcar usage optimization.

5. Communication \& data transmission systems: In this class, the positioning devices are included in various (wireless) data communication and information monitoring or managing systems.
6. Integrated train monitoring and control systems: Compared to the previous class, here positioning systems form part of a larger train operation control/management system. For example, a system may control the interaction among trains and other vehicles. In this class, GNSS/GPS-based solution may also be used as an alternative or additional positioning method.

7. General navigation \& positioning systems: Inventions in this class are most often related to track position management (e.g. determining a distance or traveling time from a current position to a target) and destination/route searching. Additionally, these systems may compare GPS-data with stored data (in order to determine the position) or create operation support data.

In addition to the patents in the above classes, 35 inventions were found to be relevant for railway operations (no common class was defined for these, however). Here, examples of utilization of GNSS/GPSbased positioning include systems for controlling train body incline (tilting) in curved track sections, measuring parameters of a track or mapping terrain, detecting oil application areas (oiling wheel flanges), monitoring railroad power system (e.g. detecting a train position on a power system in case of short-circuit accidents), monitoring, storing and transmitting information relating to railway engines, and other information recording.

Finally, I I patents were found to be not specifically related to the railway transport. That is, while the patents included the B6I identifier, their description indicated that the application was developed more generally for transport or traveling. As examples, the patent descriptions included concepts such as "portable guiding device", "travel assistant device", "mobile communication guide", "route distribution device" and "arrival announcement". 


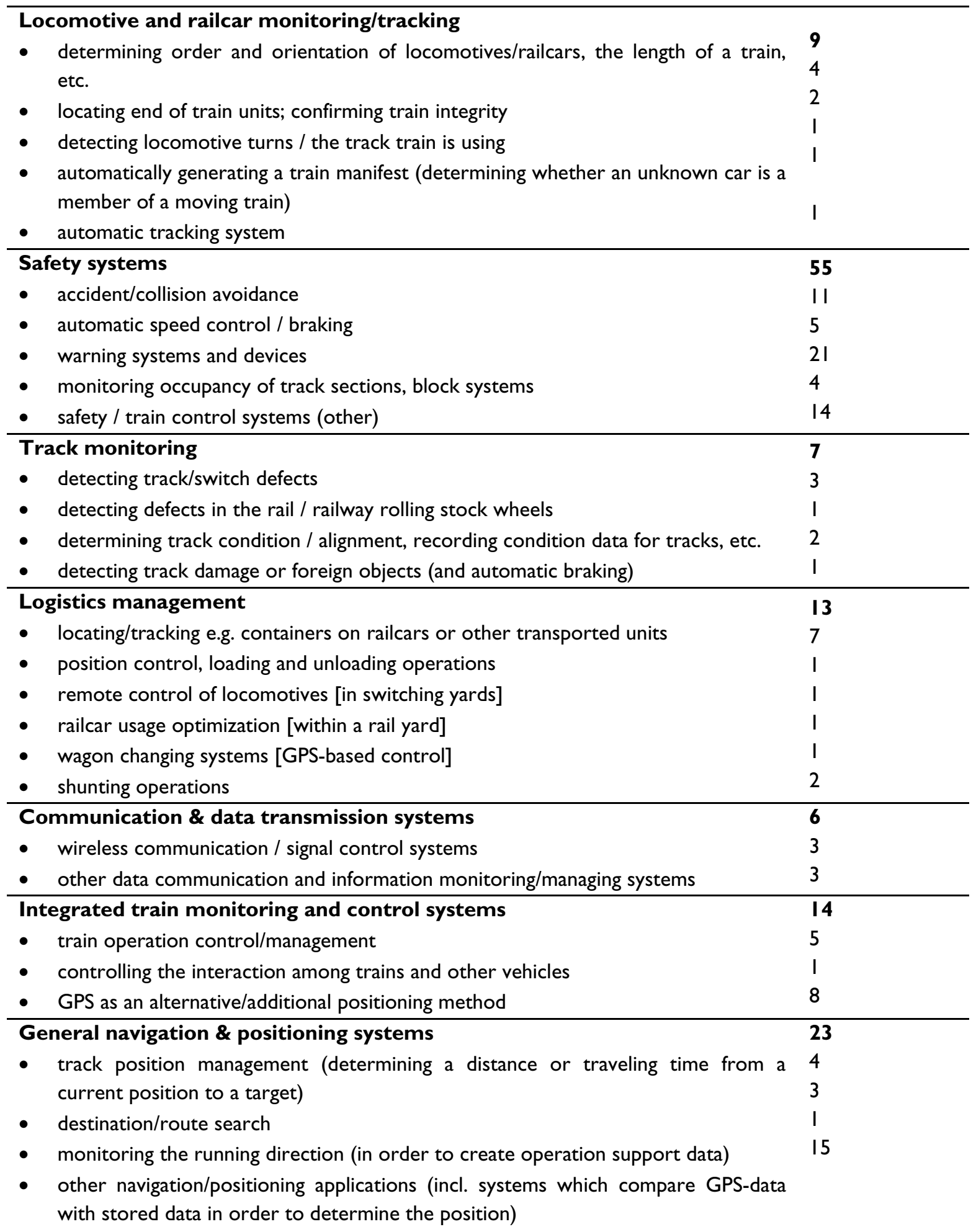




\section{Other GPS applications}

- measuring (e.g. geometric parameters of rail track), three dimensional terrain mapping, other information recording devices, train body incline [tilting] control, automatic oil-spraying, oiling devices, monitoring, storing and transmitting information relating to railway engines, railroad power system control, etc.

Table 4. The main application areas of the examined patents

\section{Conclusions}

Although the number of applications based on GNSS/GPS in railway transport has been considerably smaller than that of other modes of transportation, our analysis of the SIP database documents shows that almost 170 GNSS/GPS-related, distinct patent applications have been filed since 1994. The patenting activity in the industry was highest in 2002 with 24 applications, but has been declining in recent years. Since the amount of patent applications per year has been fairly small, however, it is difficult to estimate whether this is a temporary trend or indicates that after an initial surge of ideas the field of applications has become saturated. Moreover, by comparing this to patenting activity in the class B60 (Vehicles in general), one can see that the trend is fairly similar. Nevertheless, it is reasonable to expect that since railway transport is a 'niche area' for GNSS/GPS-related inventions, patenting activity will not increase significantly in the near future.

Regarding the nationality of the inventors, it was found that GNSS/GPS-related patenting activity has been highest in Japan (with almost $44 \%$ share of patents included in the analysis). Japan's high share was largely expected since railway research in the country has been very active both in the public and private sectors. In particular, several major Japanese corporations, such as Hitachi, Mitsubishi, Nippon Electric Co. and Matsushita have applied patents for GPS-related applications. General Electric has also been active in patenting and largely because of this the U.S. is in the second place in the number of patent applications. After Japan and the U.S., Germany, China and Great Britain were most often the countries of origin for the examined patents applications.

The analysis of the application areas of patents consisted of both examination of IPC codes and content analysis of the patent descriptions. First, the IPC codes disclosed within the patents showed that part of the inventions are not solely aimed at railway transport but can be applied to other forms of transport as well. For example, several patent descriptions indicated that the invention was designed to be used also in road transport. Secondly, both the IPC codes and the content analysis showed that ensuring or enhancing the safety of railway traffic is the most important application area for GNSS/GPS-based inventions. More specifically, the patents described various devices and systems which aim at avoiding accidents/collisions, warning train crew and other users of hazards, automatically controlling speed and applying brakes when necessary, and monitoring occupancy of track sections. Train monitoring/control systems and logistics management were found to be other major application areas for GNSS/GPS-based inventions in the railway sector. The content analysis, however, revealed also numerous other interesting applications related to e.g. track monitoring, track position management and information recording. Indeed, the variety of the types of inventions that were identified in the analysis made it difficult to assign all patents to more general classes.

Since this paper provides only an initial overview of GNSS/GPS-related patents in the railway industry, we conclude by mentioning some potential areas for further research. First, one could make additional comparisons of patenting activity between the railway sector and other modes of transportation. Our preliminary analysis suggests that the GNSS/GPS-related patenting activity in the railway sector to a large extent follows patenting trends in other sectors, but more detailed studies could identify some important differences between sectors. Comparing patents' country of origin between different transportation sectors is another possible area for future research. For example, is Japan's significant lead in patenting in the railway sector a notable exception or are there other countries that have been equally strong in patenting in other sectors of transportation? Furthermore, one could concentrate on some specific type or class of patents (e.g. collision avoidance systems) and make more detailed analysis of these inventions. Finally, one could examine 
different GNSS/GPS-based applications that are in actual use in railways nowadays and evaluate to which extent the patented inventions have been utilized in practice.

\section{References}

BEDRICH, S., Gu, X. (2004). GNSS-based sensor fusion for safety-critical applications in rail traffic, Galileo and EGNOS Information Catalogue. http://www.galileoservices.org/ library/2.I-Bedrich.pdf (Accessed I April 2009)

DEREKENARIS, G. et al. (200I). Integrating GIS, GPS and GSM technologies for the effective management of ambulances. Computers, Environment and Urban Systems, 25(3), pp. 267-278.

EC-DGTREN (2008). The Directorate-General for Energy and Transport www page for Galileo applications. http:/lec.europa.eu/dgs/energy transport/galileo/application s/rail_en.htm (Accessed I April 2009)

EULER, H.-J., Hill, C.D., Miller, U. (1996). Real-time precise GPS for railroad mapping. IEEE Position Location and Navigation Symposium, 1996, pp. 437-443.

FIRMIN, P.E. (2006). Satellite navigation technology applications for Intelligent Transport Systems: A European perspective. European Navigation Conference, Manchester, UK, 8-I0 May, 2000. http://eprints.whiterose.ac.uk/2495/ (Accessed I April 2009)

GU, X. (2005). Feasibility of GNSS/Galileo-based train location for safety relevant applications. Signal + Draht, No. I+2 / 2005, pp. 29-33.

GUO, T., Iwamura, K., Koga, M. (2007). Towards high accuracy road maps generation from massive GPS Traces data. IEEE Geoscience and Remote Sensing Symposium, 2007, Pp. 667-670.

HAUPT, R., Kloyer, M., Lange, M. (2007). Patent indicators for the technology life cycle development. Research Policy, 36(3), pp. 387-398.

HILMOLA, O.-P. (2007). European railway freight transportation and adaptation to demand decline: Efficiency and partial productivity analysis from period of 1980-2003. International Journal of Productivity and Performance Management, 56(3), pp. 205-225.
LOBO, A.X. (1998). A review of automatic vehicle location technology and its real-time applications. Transport Reviews, I8(2), pp. |65-19|.

MAKI, Y. (2005). A new train position detection system using GPS. Railway Technology Avalanche, No. 9, August I, 2005, p. 53.

MARAIS, J., Lefebvre, S., Berbineau, M. (2004). Satellite propagation path model along a railway track for GNSS applications. IEEE Vehicular Technology Conference, 2004, pP. 4066-4070.

MARWEDEL, P., Gebotys, C. (2004). Secure and safetycritical vs. insecure, non safety-critical embedded systems: Do they require completely different design approaches? Proceedings of the international conference on Hardware/Software Codesign and System Synthesis, pp. 72-73.

MINTSIS, G. et al. (2004). Applications of GPS technology in the land transportation. European Journal of Operational Research, I52(2), pp. 399-409.

NEJIKOVSKY, B., Keller, E. (2000). Wireless communications based system to monitor performance of rail vehicles. Proceedings of the ASME/IEEE Joint Railroad Conference, 2000, pp. III-I24.

PACE, S. et al. (1995). The Global Positioning System: Assessing National Policies. Rand Corporation, Santa Monica, CA.

SASAKI, K. (2005). Position detection system using GPS for carbody tilt control. Quarterly Report of RTRI, 46(2), PP. 73-77.

TAYLOR, M.A.P., Woolley, J.E., Zito, R. (2000). Integration of the global positioning system and geographical information systems for traffic congestion studies. Transportation Research Part C: Emerging Technologies, 8(I-6), Pp. 257-285.

YUAN, B.J.C., Chen, J.K.C. and Lin, L.W.C. (2007). Exploring the market development trend and technological Innovation of GPS. Proceedings of the International Conference on Business And Information. Tokyo, Japan, July 10-13, 2007. http://ibacnet.org/bai2007/proceedings/ Papers/2007bai7343.doc (Accessed I April 2009) 


\section{About the Authors}

Pekka Salmi (M.Sc.) is a researcher in the Department of Industrial Management at Lappeenranta University of Technology. His research interests focus on innovation and technology management, knowledge management and interorganizational collaboration. He has presented his works in several forums in the fields of innovation and knowledge management, and organization science..

Dr. Marko Torkkeli is a Professor of Technology and Business Innovations at the Lappeenranta University of Technology in Kouvola, Finland. His research interests focus on technology and innovation management, strategic entrepreneurship, and decision support systems. His work has been published in journals and conferences in the fields of technology management, innovation management and information systems. He has more than 100 publications to his name in these fields. He is a member of the editorial boards of Int. J. of Services Sciences and Research J. of Business Management. He is a Visiting Researcher at INESC Porto (Portugal). He serves as the Vice President of Publications of the International Society for Professional Innovation Management (ISPIM). 